\title{
PERTUMBUHAN DAN KELANGSUNGAN HIDUP BENIH IKAN NILEM (Osteochillus hasselti) YANG DIBERI PAKAN DENGAN FEEDING RATE BERBEDA
}

\section{GROWTH AND SURVIVAL RATE OF NILEM (Osteochillus hasselti) with DIFFERENT FEEDING RATE}

\author{
Y Hermawan 1a, Rosmawati 1, Mulyana ${ }^{1}$
}

1Jurusan Perikanan, Fakultas Ilmu dan Bisnis Pertanian, Universitas Djuanda Bogor, Jl. Tol Ciawi No. 1, Kotak Pos 35 Ciawi, Bogor 16720.

\begin{abstract}
ABSTRAK
Penelitian ini bertujuan untuk mengetahui feeding rate yang terbaik untuk pertumbuhan dan kelangsungan hidup benih ikan nilem. Rancangan percobaan yang digunakan pada penelitian ini adalah Rancangan Acak Lengkap (RAL) dengan 4 perlakuan dan 3 ulangan. Ikan yang digunakan adalah benih ikan nilem dengan ukuran $2-3 \mathrm{~cm}$ dengan padat tebar 120 ekor/akuarium. Perlakuan yang diberikan adalah feeding rate yang berbeda yaitu (1\%), (3\%), (5\%) dan (7\%) dari bobot biomassa ikan. Parameter yang diamati selama penelitian adalah laju pertumbuhan harian, pertumbuhan bobot mutlak, derajat kelangsungan hidup (SR), efisiensi pakan dan kualitas air. Hasil penelitian memperlihatkan bahwa perlakuan feeding rate yang berbeda memberikan pengaruh yang berbeda sangat nyata $(\mathrm{P}<0,01)$ terhadap laju pertumbuhan harian, pertumbuhan bobot mutlak dan efisiensi pakan, tetapi tidak memberikan pengaruh yang berbeda nyata $(\mathrm{P}>0,01)$ terhadap kelangsungan hidupnya. Perlakuan feeding rate7\% dari bobot biomassa ikan menghasilkan laju pertumbuhan harian terbaik yaitu 3,15\% dan kelangsungan hidup sebesar 97,8\%.

Kata kunci : feeding rate, ikan nilem, pertumbuhan, kelangsungan hidup
\end{abstract}

\section{ABSTRACT}

This studyaims to determine the best feeding rate for the growth and survival of fish seed of nilem. The experimental design in this study used completely randomized design (CRD) with 4 treatments and 3 replications. The fish used is nilem seed with a size of $2-3 \mathrm{~cm}$ with a stocking density of 120 fish/aquarium. Treatments are different feeding rate is $1 \%, 3 \%, 5 \%$, and $7 \%$ of the weight of the fish biomass. The parameters observed during the study were daily growth rate, growth absolute weight, survival rate (SR), feed efficiency and water quality. The results showed that the feeding rate of different treatment effect highly significant $(\mathrm{P}<0.01)$ on the daily growth rate, growth in absolute weight and feed efficiency, but does not give a significantly different effect $(\mathrm{P}>0.01)$ on the survival rate. Feeding rate with $7 \%$ biomass yield the best daily growth rate is $3.15 \%$ and the survival rate is $97.8 \%$.

Keywords: feeding rate, nilem, growth, survival rate

Y Hermawan, Rosmawati, Mulyana. 2015. Pertumbuhan dan kelangsungan hidup benih ikan nilem (Osteochillus hasselti) yang diberi pakan dengan feeding rate berbeda.Jurnal Mina sains ... (...): ... - .... 


\section{PENDAHULUAN}

Pemberian pakan merupakan faktor yang sangat penting dalam usaha budidaya ikan. Salah satu tindakan yang harus dilakukan untuk menunjang keberhasilan usaha pendederan ikan secara intensif adalah dengan menggunakan pakan buatan. Biaya pembelian pakan adalah pengeluaran investasi terbesar dalam biaya produksi, oleh karena itu untuk mencapai produksi semaksimal mungkin dan menguntungkan, maka perlu diperhatikan tingkat pemberian pakan (feeding rate) yang tepat untuk pertumbuhan yang optimal. Jika pakan yang diberikan terlalu sedikit, maka ikan akan tumbuh lambat dan terjadi persaingan antar ikan dalam mendapatkan pakan. Jika pakan yang diberikan berlebih, maka tidak efisien dan akan mengotori lingkungan hidup (NRC, 1977). Oleh karena itu, perlu adanya metode yang tepat agar penggunaan pakan lebih efesien dan pencemaran perairan tidak terjadi. Metode yang dapat dilakukan adalah penerapan penggunaan feeding rate yang tepat dikarenakan hal tersebut dapat meningkatkan pemanfaatan pakan yang sekaligus dapat meningkatkan keuntungan dalam usaha budidaya ikan.

Ikan nilem adalah salah satu komoditas ikan air tawar yang belum banyak dibudidayakan. Ikan nilem ini mempunyai cita rasa yang sangat sepesifik dan gurih dibandingkan ikan air tawar lainnya karena ikan ini mengandung sodium glutamat dalam daging yang terbentuk alami yang mungkin disebabkan pengaruh kebiasaan makan pakan alami plankton terutama ganggang yang tumbuh akibat pemupukan kolam. Ikan nilem tahan terhadap penyakit dan termasuk dalam kelompok omnivora.

Untuk pemberian pakan ikan nilem pada pendederan secara intensif sampai sekarang masih belum diketahui berapa feeding rateyang optimal untuk pertumbuhannya, sehingga perlu dilakukan penelitian mengenai feeding rate untuk ikan nilem supaya dapat memberikan pertumbuhan dan kelangsungan hidup yang baik.

Penelitian ini bertujuan untuk mengetahui feeding rate yang terbaik untuk pertumbuhan dan kelangsungan hidup benih ikan nilem (Osteochillus hasselti).

\section{MATERI DAN METODE}

Pemeliharaan benih ikan nilem dilakukan selama 30 hari dalam akuarium yang diaerasi di Laboratorium Budidaya Perikanan, Jurusan Teknologi Budidaya dan Bisnis Perikanan, Fakultas Ilmu dan Bisnis Pertanian, Universitas Djuanda Bogor.

Benih ikan nilem yang dipelihara berasal Balai Besar Pengembangan Budidaya Air Tawar Sukabumi-Jawa Barat dengan ukuran 2-3 cm yang dipelihara dalam akuarium yang berukuran $50 \times 30 \times 30 \mathrm{~cm}^{3}$. Pakan yang digunakan dalam penelitian ini adalah pakan komersil (Fengli 1).

Rancangan percobaan yang digunakan pada penelitian ini adalah Rancangan Acak Lengkap (RAL) dengan 4 perlakuan dan 3 ulangan. Satu satuan percobaan adalah satu akuarium yang diisi air sebanyak 30 liter dengan kepadatan ikan 120 ekor. Perlakuan yang diberikan adalah feeding rateyang berbeda, yaitu 1\%, 3\%, 5\% dan $7 \%$ dari bobot biomassa ikan.

Pemberian pakan dilakukan enam kali sehari yaitu pada jam 08.00, 10.00, 12.00, 14.00, 16.00 dan 19.00 WIB. Penyiponan dan penggantian air dilakukan dua kali sehari yaitu pada jam 06.00 dan 15.00 WIB. Suhu wadah pemeliharaan diusahakan konstan dan untuk menjaga suhu wadah pemeliharaan tersebut dipasang bokhlam lampu 40 watt pada setiap akuarium.

Benih ikan nilem yang dipelihara ditimbang setiap tujuh hari sekali untuk mengetahui pertumbuhannya, sedangkan untuk menentukan banyaknya pakan yang akan diberikan, benih ikan nilem ditimbang setiap 10 hari sekali.

Parameter yang diamati selama penelitian yaitu: laju pertumbuhan harian, pertumbuhan bobot mutlak, derajat kelangsungan hidup (SR), efisiensi pakan dan kualitas air.

Data yang diperoleh selama penelitian dianalisis dengan menggunakan analisis ragam (Anova) dan selanjutnya jika berbeda 
nyata maka untuk mengetahui perbedaan antar perlakuan digunakan uji BNT (Beda Nyata Terkecil).

\section{HASIL DAN PEMBAHASAN}

\section{Laju Pertumbuhan Harian}

Laju pertumbuhan harian (\%) rata-rata benih ikan nilem selama penelitian dapat dilihat pada Tabel 1.

Tabel 1. Laju Pertumbuhan harian (\%) benih ikan nilem selama penelitian

\begin{tabular}{ccccc}
\hline & \multicolumn{4}{c}{ Perlakuan } \\
\cline { 2 - 5 } Ulangan & $\mathbf{A}$ & $\mathbf{B}$ & $\mathbf{C}$ & $\mathbf{D}$ \\
& $\mathbf{( 1 \% )}$ & $\mathbf{( 3 \% )}$ & $\mathbf{( 5 \% )}$ & $\mathbf{( 7 \% )}$ \\
\hline $\mathbf{1}$ & $-0,36$ & 1,19 & 2,35 & 2,99 \\
$\mathbf{2}$ & $-0,60$ & 1,24 & 2,69 & 3,18 \\
$\mathbf{3}$ & $-0,89$ & 1,20 & 2,56 & 3,28 \\
\hline Rata-rata & $\mathbf{- 0 , 6 2}^{\mathbf{a}}$ & $\mathbf{1 , 2 1}^{\mathbf{b}}$ & $\mathbf{2 , 5 3}$ & $\mathbf{3 , 1 5}$ \\
\hline
\end{tabular}

Keterangan: superskrip huruf yang berbeda menunjukkan berbeda sangat nyata $(\mathrm{P}<0,01)$

Hasil uji analisis ragam menunjukkan bahwa perlakuan feeding rateyang berbeda (1\%, 3\%, 5\% dan 7\%) memberikan pengaruh yang berbeda sangat nyata $(\mathrm{P}<0,01)$ terhadap laju pertumbuhan harian rata-rata benih ikan nilem. Hasil uji BNT juga menyebutkan bahwa terdapat perbedaan yang nyata pada setiap perlakuannya $(1 \%, 3 \%, 5 \%$ dan $7 \%)$.

Hasil penelitian Ismayadi (2012) memperlihatkan bahwa benih ikan nilem dengan berat rata-rata 2,30 gram yang dipelihara di akuarium dengan kepadatan 3 ekor/liter memberikan laju pertumbuhan harian sebesar 1,9\%. Laju pertumbuhan harian pada penelitian ini lebih tinggi dibandingkan hasil penelitian Ismayadi, hal ini diduga karena pada penelitian ini menggunakan ikan yang berukuran lebih kecil dibandingkan ikan pada penelitian Ismayadi.

\section{Pertumbuhan Bobot Mutlak}

Pertumbuhan bobot mutlak (gram) ratarata benih ikan nilem selama penelitian dapat dilihat pada Tabel 2.

Tabel 2. Pertumbuhan bobot (gram) mutlak benih ikan nilem selama penelitian

\begin{tabular}{ccccc}
\hline & \multicolumn{4}{c}{ Perlakuan } \\
\cline { 2 - 5 } Ulangan & $\mathbf{A}$ & $\mathbf{B}$ & $\mathbf{C}$ & $\mathbf{D}$ \\
& $\mathbf{( 1 \% )}$ & $\mathbf{( 3 \% )}$ & $\mathbf{( 5 \% )}$ & $\mathbf{( 7 \% )}$ \\
\hline $\mathbf{1}$ & $-0,037$ & 0,150 & 0,350 & 0,507 \\
$\mathbf{2}$ & $-0,055$ & 0,154 & 0,426 & 0,547 \\
$\mathbf{3}$ & $-0,080$ & 0,145 & 0,413 & 0,599 \\
\hline $\begin{array}{c}\text { Rata- } \\
\text { rata }\end{array}$ & $\mathbf{- 0 , 0 5 7 ^ { \mathbf { a } }}$ & $\mathbf{0 , 1 5 0}$ & $\mathbf{0 , 3 9 6}$ & $\mathbf{0 , 5 5 1 ^ { \mathbf { d } }}$ \\
\hline
\end{tabular}

Keterangan: superskrip huruf yang berbeda menunjukkan berbeda sangat nyata

$(\mathrm{P}<0,01)$

Hasil uji analisis ragam menunjukkanbahwa perlakuan feeding rate yang berbeda $(1 \%, 3 \%, 5 \%$ dan $7 \%)$ memberikan pengaruh yang berbeda sangat nyata $(\mathrm{P}<0,01)$ terhadap pertumbuhan bobot mutlak rata-rata benih ikan nilem. Hasil uji BNT juga menyebutkan bahwa terdapat perbedaan yang nyata pada setiap perlakuannya $(1 \%, 3 \%, 5 \%$ dan $7 \%)$.

Hasil penelitian Ismayadi (2012) memperlihatkan bahwa benih ikan nilem dengan berat rata-rata 2,30 gram yang dipelihara di akuarium dengan kepadatan 3 ekor/liter memberikan pertumbuhan bobot mutlak sebesar 1,77 gram. Pertumbuhan bobot mutlak pada penelitian ini lebih kecil dibandingkan dengan hasil penelitian Ismayadi, hal ini diduga karena pada penelitian ini menggunakan ikan yang berukuran lebih kecil dibandingkan ikan pada penelitian Ismayadi.

Perlakuan feeding rate $1 \%$ memperlihatkan penurunan laju pertumbuhan harian dan pertumbuhan bobot mutlak benih ikan nilem, hal ini diduga karena ikan yang dipelihara mengalami kekurangan asupan energi dari makanan sehingga mendorong ikan untuk mengambil cadangan energi dari dalam tubuhnya sendiri untuk kebutuhan pokok 
yaitu mempertahankan hidup dan untuk pemeliharaan tubuhnya. Arofah (1991) menyatakan bahwa pertumbuhan ikan dapat terjadi jika jumlah makanan yang dimakan melebihi kebutuhan untuk pemeliharaan tubuh. Fujaya (2000) menjelaskan, tidak semua makanan yang dimakan oleh ikan digunakan untuk pertumbuhan. Sebagian besar energi dari makanan digunakan untuk pemeliharaan, sisanya untuk aktivitas, pertumbuhan dan reproduksi.

Perlakuan feeding rate $3 \%$ dan $5 \%$ memperlihatkan laju pertumbuhan harian dan pertumbuhan bobot mutlak yang meningkat meskipun pertumbuhannya lebih rendah dari perlakuan $7 \%$, hal ini diduga karena jumlah pakan yang diberikan masih belum mencukupi kebutuhan ikan untuk tumbuh secara optimal.

Perlakuan feeding rate $7 \%$ memperlihatkan laju pertumbuhan harian dan pertumbuhan bobot mutlak yang paling tinggi, hal ini diduga karena pakan yang diberikan jumlahnya sesuai dengan kebutuhan ikan untuk tumbuh secara optimal. Dengan demikian, energi yang diperoleh dari pakan selain dapat digunakan untuk memelihara tubuh, pegerakan ikan dan mengganti sel-sel yang rusak, juga dapat digunakan untuk tumbuh secara optimal. Huet (1971) mengatakan bahwa tingkat pemberian pakan yang sesuai dengan kebutuhan ikan akan memberikan pertumbuhan yang optimal.

\section{Derajat Kelangsungan Hidup}

Derajat kelangsungan hidup (\%) ratarata benih ikan nilem selama penelitian dapat dilihat pada Tabel 3.

Tabel 3. Derajat kelangsungan hidup (\%) benih ikan nilem selama penelitian

\begin{tabular}{ccccc}
\hline & \multicolumn{4}{c}{ Perlakuan } \\
\cline { 2 - 5 } Ulangan & $\mathbf{A}$ & $\mathbf{B}$ & $\mathbf{C}$ & $\mathbf{D}$ \\
& $\mathbf{( 1 \% )}$ & $\mathbf{( 3 \% )}$ & $\mathbf{( 5 \% )}$ & $\mathbf{( 7 \% )}$ \\
\hline $\mathbf{1}$ & 70,0 & 95,0 & 97,5 & 99,2 \\
$\mathbf{2}$ & 89,2 & 99,2 & 98,3 & 97,5
\end{tabular}

\begin{tabular}{ccccc}
$\mathbf{3}$ & 85,8 & 95,8 & 98,3 & 96,7 \\
\hline Rata-rata & $\mathbf{8 1 , 7}^{\mathbf{a}}$ & $\mathbf{9 6 , 7}^{\mathbf{a}}$ & $\mathbf{9 8 , 0}^{\mathbf{a}}$ & $\mathbf{9 7 , 8}^{\mathbf{a}}$ \\
\hline
\end{tabular}

Keterangan: superskrip huruf yang sama menunjukkan tidak berbeda nyata $(\mathrm{P}>0,01)$

Hasil uji analisis ragam menunjukkan bahwa perlakuan feeding rate yang berbeda $(1 \%, 3 \%, 5 \%$ dan $7 \%)$ tidak memberikan pengaruh yang berbeda nyata $(\mathrm{P}>0,01)$ terhadap kelangsungan hidup benih ikan nilem.

Hasil penelitian Ismayadi (2012) memperlihatkan bahwa benih ikan nilem dengan berat rata-rata 2,30 gram yang dipelihara di akuarium dengan kepadatan 3 ekor/liter memberikan tingkat kelangsungan hidup sebesar 100\%. Derajat kelangsungan hidup pada penelitian ini lebih kecil dibandingkan hasil penelitian Ismayadi, hal ini diduga karena pada penelitian ini menggunakan ikan yang berukuran lebih kecil dibandingkan ikan pada penelitian Ismayadi.

Pada perlakuan feeding rate 1\% terdapat banyak kematian ikan, hal ini diduga karena energi yang dibutuhkan oleh ikan untuk mempertahankan hidup dan pemeliharaan tubuhnya kurang, sehingga ikan tersebut tidak dapat mempertahankan kelangsungan hidupnya. Effendie (2002) mengatakan bahwa energi yang diperoleh dari pakan yang dikonsumsi pertama-tama akan digunakan untuk memelihara tubuh, pergerakan ikan dan mengganti sel-sel yang rusak, selebihnya digunakan untuk pertumbuhan. Zonneveld et al. (1991) menyatakan bahwa tinggi rendahnya kelangsungan hidup dipengaruhi faktor luar salah satunya adalah kualitas dan kuantitas pakan.

Kematian ikan pada perlakuan feeding rate 3\%, 5\% dan 7\% diduga karena masih terjadi persaingan di dalam mendapatkan makanan, dimana ikan yang ukurannya lebih besar akan mendominasi dalam mendapatkan makanan. 


\section{Efisiensi Pakan}

Efisiensi pakan rata-rata benih ikan nilem selama penelitian dapat dilihat pada Tabel 4.

Tabel 4. Tingkat efisiensi pakan benih ikan nilem selama penelitian

\begin{tabular}{ccccc}
\hline & \multicolumn{4}{c}{ Perlakuan } \\
\cline { 2 - 5 } Ulangan & $\mathbf{A}$ & $\mathbf{B}$ & $\mathbf{C}$ & $\mathbf{D}$ \\
& $\mathbf{( 1 \% )}$ & $\mathbf{( 3 \% )}$ & $\mathbf{( 5 \% )}$ & $\mathbf{( 7 \% )}$ \\
\hline $\mathbf{1}$ & $-1,45$ & 0,35 & 0,56 & 0,50 \\
$\mathbf{2}$ & $-1,00$ & 0,43 & 0,47 & 0,53 \\
$\mathbf{3}$ & $-1,27$ & 0,38 & 0,57 & 0,55 \\
\hline Rata-rata & $\mathbf{- 1 , 2 4}^{\mathbf{a}}$ & $\mathbf{0 , 3 9}^{\mathbf{b}}$ & $\mathbf{0 , 5 3}$ & $\mathbf{0 , 5 3}$ \\
\hline
\end{tabular}

Keterangan: superskrip huruf yang sama menunjukkan tidak berbeda nyata $(\mathrm{P}>0,01)$

Hasil uji analisis ragam menunjukkan bahwa perlakuan feeding rate yang berbeda (1\%, 3\%, 5\% dan 7\%) memberikan pengaruh yang berbeda sangat nyata $(\mathrm{P}<0,01)$ terhadap efisiensi pakan benih ikan nilem. Hasil uji BNT juga menyebutkan bahwa perlakuan A (1\%) berbeda sangat nyata dengan perlakuan lainnya, sedangkan perlakuan B (3\%) tidak berbeda nyata dengan $\mathrm{C}(5 \%)$ dan $\mathrm{D}(7 \%)$.

Efisiensi pakan menunjukkan seberapa besar pakan yang dapat dimanfaatkan oleh ikan untuk pertumbuhan. Nilai efisiensi pakan yang sangat rendah pada perlakuan feeding rate $1 \%$ diduga karena ikan kekurangan asupan energi dari makanan, dimana energi yang diperoleh dari pakan hanya sebagian kecil yang dapat digunakan untuk kebutuhan pokok, hal tersebut dapat dilihat dari pertumbuhan yang menurun dan tingkat kelangsungan hidup yang rendah pada perlakuan feeding rate $1 \%$. Oleh karena itu ikan memerlukan pakan dengan jumlah yang lebih banyak untuk dapat mempertahankan hidup dan meningkatkan beratnya.

Nilai efisiensi pakan yang relatif rendah pada perlakuan feeding rate $3 \%$ diduga karena ikan masih kekurangan asupan energi dari makanan tetapi masih mencukupi untuk kebutuhan pokok dilihat dari masih adanya pertumbuhan. Ikan yang diberi pakan 3\% dari bobot biomassa masih memerlukan pakan dengan jumlah yang lebih banyak lagi untuk dapat meningkatkan beratnya secara optimal.

Nilai efisiensi pakan yang tinggi pada perlakuan feeding rate $5 \%$ dan $7 \%$ diduga karena terjadi kelebihan energi yang diperoleh dari makanan yang dikonsumsi oleh ikan, sehingga energi tersebut dapat digunakan untuk pertumbuhan yang optimal. Meskipun nilai laju pertumbuhan harian dan pertumbuhan bobot mutlaknya paling tinggi tetapi nilai efisiensi pakan pada perlakuan feeding rate $7 \%$ sama dengan perlakuan $5 \%$, hal ini menunjukkan bahwa pakan yang diberikan dimanfaatkan sama besarnya untuk pertumbuhan.

\section{Kualitas Air}

Berdasarkan hasil analisis kualitas air selama penelitian berlangsung menunjukkan bahwa parameter-parameter kualitas air yang diukur masih berada dalam kisaran nilai toleransi untuk mendukung kehidupan dan pertumbuhan benih ikan nilem.

\begin{tabular}{c|c|c|c|c}
\hline \multirow{2}{*}{$\begin{array}{c}\text { Parameter } \\
\text { Kualitas }\end{array}$} & \multicolumn{4}{|c}{$\begin{array}{c}\text { Perlakuan Jumlah Pemberian } \\
\text { Pakan Benih Ikan Nilem }\end{array}$} \\
\cline { 2 - 5 } Air & $\mathbf{1 \%}$ & $\mathbf{3 \%}$ & $\mathbf{5 \%}$ & $\mathbf{7 \%}$ \\
\hline Suhu (0) & $26,5-$ & $26,5-$ & $26,5-$ & $26,5-$ \\
& 30,5 & 30,5 & 30,5 & 30,5 \\
DO (ppm) & $4,66-$ & $4,50-$ & $4,66-$ & $4,23-$ \\
& 4,68 & 4,90 & 4,99 & 4,98 \\
pH & $7,4-7,5$ & $7,4-7,5$ & $7,2-7,5$ & $6,4-7,5$ \\
NH$_{3}(\mathbf{p p m})$ & $0,020-$ & $0,023-$ & $0,025-$ & $0,030-$ \\
& 0,038 & 0,037 & 0,045 & 0,050 \\
\hline
\end{tabular}

\section{KESIMPULAN}

Perlakuan feeding rate $7 \%$ dari bobot biomassa ikan menghasilkan pertumbuhan dan tingkat kelangsungan hidup yang baik untuk benih ikan nilem yang berukuran 2-3 cm yaitu masing-masing sebesar 0,551 gram dan $97,8 \%$. 


\section{DAFTAR PUSTAKA}

Arofah YH. 1991. Pengaruh Jumlah Pakan dan Frekuensi Pemberian Pakan yang Berbeda terhadap Pertumbuhan dan Kelangsungan Hidup Ikan Kakap Putih (Lates calcalifer). Skripsi. Fakultas Peternakan, Universitas Diponegoro. Semarang.

Effendie MI. 2002. Biologi Perikanan. Bogor: Yayasan Pustaka Nusantara.

Fujaya. 2000. Fisiologi Ikan. Yogyakarta: Kanisius.

Huet M. 1971. Texbook of Fish Culture: Breeding and Cultivation of Fish. England: Fishing News Book Ltd.

Ismayadi A. 2012. Kelangsungan Hidup dan Pertumbuhan Benih Ikan Nilem (Osteochillus hasselti) yang Dipelihara dengan Kepadatan Berbeda. Skripsi. Fakultas Pertanian, Universitas Djuanda Bogor. Bogor.
NRC (National Research Council). 1977. Nutrient Requirements of Warmwater Fishes. Washington D.C: National Academy of Sciences.

Pratiwi, Rosita R, Dhahiyat Y. 2011. Pengaruh Tingkat Pemberian Pakan Terhadap Pertumbuhan dan Deposisi Logam Berat pada Ikan Nilem di Keramba Jaring Apung Waduk Ir. H. Djuanda. Jurnal Akuatika Volume 2/September 2011.

Zonneveld N, Huisman EA, Boon JH. 1991. Prinsip-prinsip Budidaya Ikan. Jakarta: Gramedia Pustaka Utama. 